\title{
Bronchial Cast Formation in Plastic Bronchitis
}

\author{
Patricia Demont $^{a}$ Tobias Fehr ${ }^{b}$ Thomas Geiser ${ }^{a}$ Sebastian R. Ott ${ }^{a}$ \\ Departments of a Pulmonary Medicine and ${ }^{\mathrm{b}}$ Intensive Care Medicine, University Hospital Bern (Inselspital), \\ University of Bern, Bern, Switzerland
}

\section{Key Words}

Plastic bronchitis · Lymphatic malformation . Lymphangiography · Thoracic duct ligation
The most common cause of bronchial cast formation is plastic bronchitis. In our case, severe respiratory insufficiency occurred 1 day after elective laparoscopic cholecystectomy in a 35-year-old man with a history of recurrent pulmonary infections, leading to acute hypercapnic
Fig. 1. a CT scan showing bronchial casts filling both the main bronchus down to the basal segment bronchi. b Flexible bronchoscopy through the endotracheal tube: vast cast in the distal trachea expanding in the main bronchi. c Cast extracted from the left main bronchus by flexible bronchoscopy through the endotracheal tube using a cryoprobe. d Lymphography demonstrating atypical drainage from the ductus thoracicus mainly via the left lung.
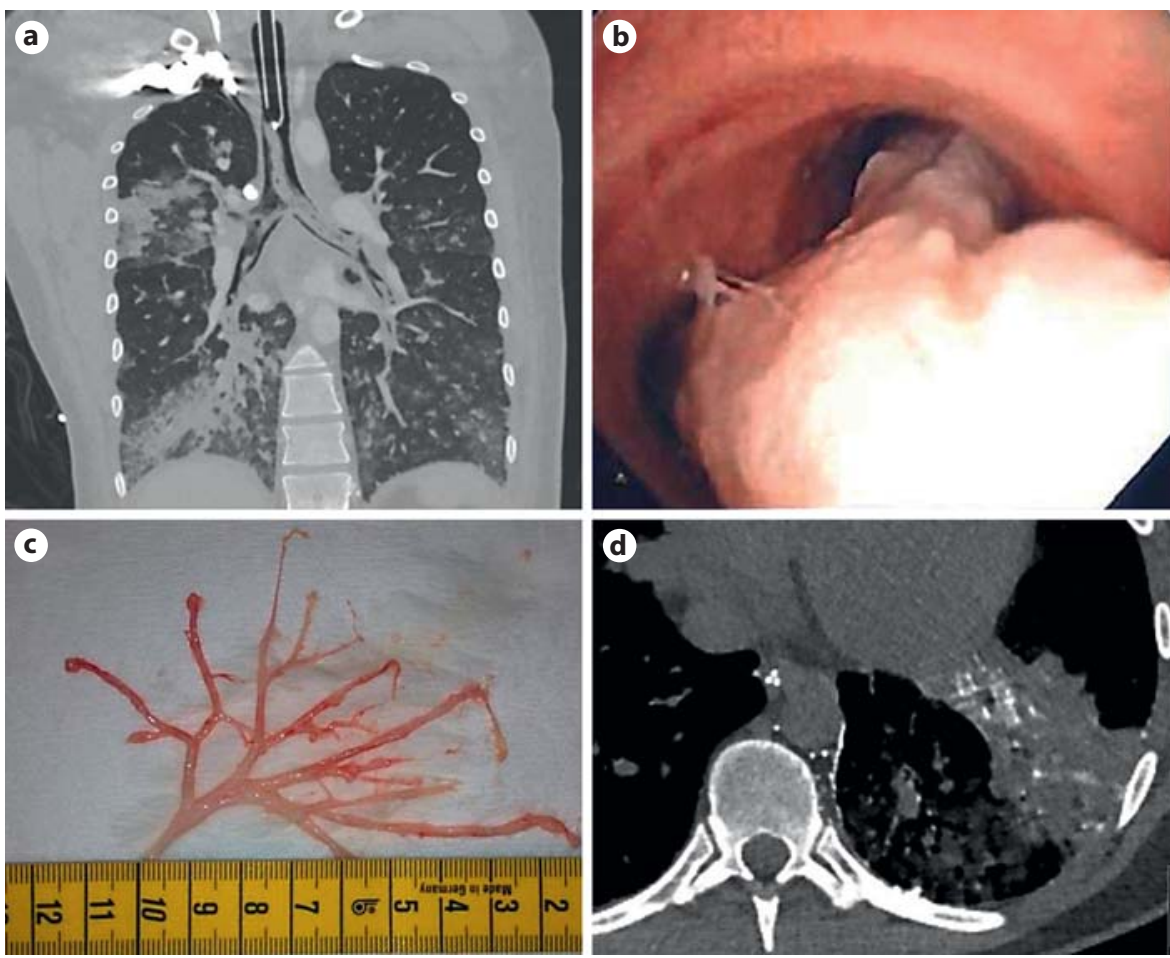

\section{KARGER}

E-Mail karger@karger.com www.karger.com/res
Sebastian R. Ott, MD

Department of Pulmonary Medicine, Inselspital University Hospital Bern

CH-3010 Bern (Switzerland)

E-Mail sebastian.ott@insel.ch 
respiratory failure $\left(\mathrm{pCO}_{2} 62 \mathrm{~mm} \mathrm{Hg}, \mathrm{pH} 7.22\right)$, necessitating immediate intubation and mechanical ventilation. A chest CT scan showed bilateral infiltrates. Antibiotics failed to improve the patient's respiratory condition. Two days later, a follow-up CT scan was performed due to difficult ventilation, revealing large, branching bronchial casts (fig. 1a). A vast cast was removed by flexible bronchoscopy through the endotracheal tube using a cryoprobe (fig. 1b, c). Recurrent cast formation necessitated multiple bronchoscopies. Histologically, the casts consisted of fibrin with only a few lymphocytes and macrophages with lipid inclusions. Together with a drainage of a white fluid rich in triglycerides from the left lower lobe, this picture suggested a lymphatic origin of the casts. Initiation of complete parenteral low-fat nutrition lead to reduced cast formation. Mediastinal lymphography confirmed atypical drainage from the ductus thoracicus mainly via the left lung (fig. 1d), leading to surgical ligature of the ductus thoracicus. Thereafter, enteral nutrition was re-established without any evidence of relapse of plastic bronchitis.
Bronchitis plastica is a rare disorder characterized by formation of large, branching bronchial casts, which are often expectorated, but may be discovered only by bronchoscopy in some cases. Cast formation is mainly secondary to underlying diseases of the lung, heart, or lymph vessels such as asthma bronchiale, pneumonia, allergic bronchopulmonary aspergillosis, bronchiectasis, mucoviscidosis, tuberculosis, cardiac insufficiency, and valvular disease $[1,2]$. Therefore, a careful search for an underlying condition is the key to successful treatment. Only sufficient treatment of the underlying disease terminates cast formation and allows a complete resolution $[1,2]$.

\footnotetext{
References

Seear M, Hui H, Magee F, Bohn D, Cutz E: Bronchial casts in children: a proposed classification based on nine cases and a review of the literature. Am J Respir Crit Care Med 1997; 155:364-370.

2 Madsen P, Shah SA, Rubin BK: Plastic bronchitis: new insights and a classification scheme. Paediatr Respir Rev 2005;6:292-300.
} 